\title{
Cerebellopontine Angle
}

National Cancer Institute

\section{Source}

National Cancer Institute. Cerebellopontine Angle. NCI Thesaurus. Code C54057.

A region of the brain at the junction of the pons, cerebellum, and medulla. It is a frequent site of tumor formation. 